\title{
PERIODIZAÇÃO DA DEPENDÊNCIA E PADRÃO DE REPRODUÇÃO DO CAPITALISMO ${ }^{1}$
}

Fabio de Oliveira Maldonado ${ }^{2}$

Resumo: O presente estudo retoma o debate sobre a necessidade metodológica de uma periodização da dependência latino-americana. Apesar de algumas categorias de análise terem sido esboçadas para dar conta de historicizar o capitalismo dependente, tentou-se expor nesse artigo a predominância do âmbito econômico em noções como padrão de reprodução do capital que, é verdade, consiste numa contribuição efetiva para o estudo das etapas históricas da dependência. Para que o estudo pudesse avançar, foi realizado um debate sobre a necessidade de precisar a importância dos diferentes graus de abstração e suas respectivas categorias para cada objetivo analítico. Ao fim, foi proposto uma nova noção que viabilize identificar as regularidades da reprodução do capitalismo dependente nas diferentes etapas históricas, constituindo-se em um nível mais concreto de análise em relação ao padrão de reprodução do capital

Palavras-chave: Teoria Marxista da Dependência. Ruy Mauro Marini. Periodização da dependência. Padrão de reprodução do capital. Padrão de reprodução do capitalismo.

Abstract: The present study retakes the debate about methodological need of Latin-American dependency periodization. Despite some analysis categories has been outlined to get historically the dependency capitalism, this article tried to expose the predominance of the economic scope in notions like pater of capital reproduction, which in truth, consists in an effective contribution to the study of historical steps of dependency. That the study could advance, was accomplished a debate about the necessity to specify the importance of the different degrees of abstraction and yours respective categories for each analytical goal. At the end, was proposed a new notion that makes feasible identify reproduction of dependency capital regularities in different historical steps, constituting in a more concrete level of analysis in relation to pattern of capital reproduction. Keywords: Marxist Theory of Dependency. Ruy Mauro Marini. Dependency's periodization. Pattern of capital reproduction. Pattern of capitalism reproduction.

${ }^{1} \mathrm{O}$ presente artigo é resultado da pesquisa realizada durante o mestrado, defendida em formato de dissertação no Programa de Pós-Graduação em Integração da América Latina da Universidade de São Paulo (PROLAM/USP).

2 Mestre no Programa de Pós-Graduação em Integração da América Latina da Universidade de São Paulo, (PROLAM-USP). Membro do Núcleo de Trabalho e Pesquisa sobre a Práxis e Dialética de Marx (Núcleo Práxis), vinculado ao Laboratório de Economia Política e História Econômica da Universidade de São Paulo (LEPHEUSP). Também é membro do Núcleo de Estudos Sobre o Capitalismo Dependente (NECAD). 
Se tutto deve rimanere com'è, è necessario che tutto cambi.

Giuseppe di Lampedusa.

\section{Intraduçãu}

O movimento de retomada e revitalização da Teoria Marxista da Dependência é uma empresa que não pode ser negligenciada e que, de fato, parece reoxigenar a reflexão crítica e o debate sobre a realidade latino-americana. Essa edição especial dos Cadernos do Centro de Estudos Rurais e Urbanos (CERU) dedicada a homenagear os 20 anos da morte de Ruy Mauro Marini; o Seminário "Teoria Marxista da Dependência: um resgate do exílio", organizado pelo Núcleo de Estudos Sobre o Capitalismo Dependente (NECAD) e realizado em 2016 na Universidade de São Paulo (USP), com a participação de professores e intelectuais de diversas regiões do Brasil, alguns mais jovens e outros com décadas de estudo sobre as contradições do capitalismo dependente, e com a participação de Teotônio dos Santos, um dos maiores intelectuais brasileiros e latino-americanos, e um dos fundadores dessa corrente teórica, e com o intelectual argentino Cláudio Katz, contando ainda com a participação de mais de 600 pessoas em três dias; a adoção da bibliografia de autores como Ruy Mauro Marini, André Gunder Frank, Vânia Bambirra e o próprio Theotonio dos Santos em grades curriculares em disciplinas em cursos de graduação e pós-graduação como o de Ciência Política e do Programa de Pós-Graduação em Integração da América Latina (PROLAM), ambos da USP - ainda muito tributária ao pensamento de Fernando Henrique Cardoso e, de certa forma, responsável pela associação imediata da Teoria da Dependência à imagem de Cardoso; o curso "Dependência na América Latina: um museu de grandes novidades" - também organizado pelo NECAD - realizado no Centro de Pesquisa e Formação do SESCSP; a adoção de determinadas categorias, como a de superexploração do trabalho, na análise de alguns partidos, organizações políticas e movimentos sociais; são algumas evidências, para ficar apenas em São Paulo, de como a Teoria Marxista da Dependência vem paulatinamente recuperando uma certa importância e espaço.

Não temos a intenção de precisar os motivos históricos dessa 
recuperação, mas ao constatar a retomada da vitalidade dos estudos da dependência, também estamos seguros de que novas (e antigas) críticas serão mobilizadas para dialogar e debater com essa corrente teórica. Em realidade, no campo crítico das ciências econômicas e sociais, já surgem artigos e alguns trabalhos de dissertação e tese que se preocupam em debater de maneira crítica com a Teoria Marxista da Dependência (TMD), o que é uma notícia benfazeja, ainda que haja casos de excessos ou com preocupações outras que acabam deixando o caráter científico do debate na geladeira. Por outro lado, parece existir no seio da própria Teoria Marxista da Dependência, divergências teóricas que estão suscitando debates de extrema relevância para a qualificação da análise do capitalismo dependente.

Foi animado por duas questões principais relacionadas ao debate mencionado que apresentamos alguns esboços, quase rascunhos iniciais, nesse artigo. Por um lado, existe ainda um debate latente, não totalmente desenvolvido e explicitado de um setor crítico da esquerda que não adere a proposta teórica da TMD, que tende a conceber as formulações de Ruy Mauro Marini como a-históricas, esquemáticas ou até metafísicas, o que, de certa forma, nos inspira a criar um diálogo fraterno com esse setor ${ }^{1}$. Por outro lado, na esteira do debate necessário dentro dessa corrente teórica e fazendo jus a proposição de Marini, no Post scriptum de Dialética da Dependência, em formular uma Teoria Marxista da Dependência - o que poderia indicar que tem um amplo terreno aberto para se avançar -, avaliamos que o debate histórico do capitalismo dependente não é de menor importância e o exercício de periodização da dependência ainda é uma tarefa incompleta.

Como será possível ver, essa última afirmação não significa que concordamos com as críticas a Ruy Mauro Marini, em particular, e a TMD, em geral, que afirmam que suas análises primam pela teoria em detrimento a história, enfim que são a-históricas. Ao ler a Dialética da Dependência com cuidado, percebe-se o esforço de elaborar categorias ${ }^{1}$ Como será possível constatar na entrevista com Juan Cristóbal Cárdenas Castro, professor de economia da Universidade do Chile, essa é uma polêmica antiga que, de certa maneira, foi gestada no Chile, no final da década de 1960 e primeira metade da década de 1970. Cabe lembrar que Ernesto Laclau era um dos membros do Centro de Estudos da Realidade Nacional (CEREN), sendo um dos autores que critica uma certa insuficiência na análise histórica de André Gunder Frank em Capitalismo e Subdesenvolvimento na América Latina.

A entrevista com Juan Cristóbal está publicada nessa edição dos cadernos do CERU. $C f$. "50 anos do giro dependentista -entrevista com Juan Cristóbal Cárdenas Castro". 
mais gerais que permitem analisar o capitalismo dependente latinoamericano em diversos momentos históricos. Em outras palavras, Marini está realizando uma reflexão com um grau de abstração mais elevado, mas que tem conexão direta com a história do capitalismo latino-americano. Mesmo que não se entenda dessa forma, somente quem não leu artigo $O$ ciclo do capital na economia dependente ${ }^{2}$ (1979), pode incorrer no erro de realizar tais tipos de assertivas.

Esclarecido isto, entendemos que a categoria padrão de reprodução do capital, apesar do avanço que propiciou para a apreensão dos movimentos históricos do capitalismo dependente, não dá conta de periodizá-lo. Diante disso, a proposição do presente artigo consiste em levantar um debate de método sobre a periodização da dependência, o que implica em tratar da importância de localizar os níveis de abstração condizentes com cada proposta analítica e que vá iluminando as múltiplas determinações que incidem sobre o capitalismo latino-americano.

\section{Periadizaçăa da dependência: um debate teárica e de métada}

Durante o final dos anos 1960 e durante os anos 1970, muito se avançou na compreensão da história e da estrutura econômica e social dos países latino-americanos. Expropriação do valor produzido internamente por meio do intercâmbio desigual e da transferência de valor, superexploração da força de trabalho, o recurso ao subimperialismo, foram algumas das principais descobertas científicas desse período. Não temos a intenção de fazer um resgate histórico do surgimento da Teoria da Dependência, o que exigiria promover um debate com as teorias da modernização e do desenvolvimento, e com as formulações político-teóricas dos Partidos Comunistas até a década de 1960. Entendemos não ser necessário retomar o tema, já que esse debate está bem registrado ${ }^{3}$. Tampouco nos deteremos numa reflexão

${ }^{2}$ Ruy Mauro Marini. O ciclo do capital na economia dependente. In: Carla Ferreira, Jaime Osorio, Mathias Luce (Orgs.). Padrão de reprodução do capital. São Paulo: Boitempo, 2012.

${ }^{3}$ Cf. Theotonio dos Santos. A teoria da dependência: balanço e perspectivas, 2015. Ricardo Bielschowsky. Pensamento econômico brasileiro: o ciclo do desenvolvimentismo, 2000. $C f$. Michael Löwy. O marxismo na América Latina: uma 
mais detalhada sobre a caracterização do conceito de dependência, passando por este somente na medida em que for necessário definir o seu conteúdo para estabelecer a concretude das sociedades latinoamericanas diante do seu movimento histórico. Em realidade, nosso objetivo consiste em propor um debate mais amplo sobre a periodização do capitalismo dependente na região.

Ainda que não nos detenhamos no resgate histórico do surgimento da Teoria da Dependência e mais especificamente da Teoria Marxista da Dependência, cabe relembrar que o estudo sobre a história do capitalismo dependente teve como um de seus catalisadores a crítica à concepção do modo de produção feudal ou semifeudal e suas derivações teóricas e políticas, defendida pelos partidos comunistas da região. Em seu trabalho mais conhecido, Capitalismo e subdesenvolvimento na América Latina (1978), André Gunder Frank tem em mente realizar uma crítica a esse modelo teórico, apontando para uma reorientação política e econômica. Diante do impacto que o livro causou na esquerda latino-americana e do debate que suscitou no final da década de 1960, Ernesto Laclau observa que a reflexão de Frank resultou em três tipos de afirmações: "1. A América Latina teve, desde o início, uma economia de mercado. 2. A América Latina foi capitalista desde sua origem ${ }^{4} ; 3$. A natureza dependente de sua inserção

antologia de 1909 aos dias atuais, 2012. Löwy introduz as diversas linhagens do marxismo latino-americano, retomando diversos documentos que ilustram as linhas políticas dos partidos comunistas à época.

${ }^{4}$ Se Ernesto Laclau concorda com o fato de que a América Latina sempre esteve inserida na economia de mercado, exercendo um papel determinado no capitalismo mercantil, ele centra sua crítica na segunda assertiva, a saber, a compreensão de que a América Latina foi uma economia capitalista desde a conquista ibérica.

"O que, inicialmente, nos parece surpreendente é que Frank prescinde totalmente das relações de produção em suas definições de capitalismo e feudalismo. Em face disto, sua caracterização anterior da relação entre exploradores e explorados como a contradição fundamental do capitalismo, deixa de ser tão surpreendente".

"Porque, para Marx - como é óbvio para todos os que tenham um conhecimento ainda que superficial de seu trabalho - o capitalismo era um modo de produção. A relação econômica fundamental do capitalismo é constituída pela venda, pelo trabalhador livre, de sua força de trabalho, cuja precondição necessária é a perda da propriedade dos meios de produção pelo produtor direto".

Nesse sentido, diz Laclau: 
no mercado capitalista mundial é a causa de seu subdesenvolvimento" (1978, p. 23). Para o nosso interesse imediato, nos deteremos rapidamente no terceiro ponto.

Embora se possa dizer que, desde o período colonial haja uma continuidade na situação de subordinação das sociedades latinoamericanas em relação às metrópoles, é somente a partir do período que corresponde a independência formal dos países da região e a revolução industrial na Europa, que as relações da América Latina com o centro capitalista europeu foram adquirindo uma estrutura definida, de modo que será, "a divisão internacional do trabalho, que determinará o curso do desenvolvimento ulterior da região. Em outros termos, é a partir de então que se configura a dependência"s (MARINI, 1982,p. 18).

"Para Marx, a acumulação de capital comercial é perfeitamente compatível com os mais variados modos de produção e de maneira alguma pressupõe a existência de um modo de produção capitalista".

Ernesto Laclau. Política e ideologia na teoria marxista: capitalismo, fascismo e populismo. Rio de Janeiro: Paz e Terra, 1978, p. 26, 27 e 28.

Sem aprofundarmos esse debate, cabe salientar que, a partir dessa reflexão, Laclau reafirma a predominância do caráter feudal do modo de produção da América Latina, se afastando, no entanto, das teses reformistas dos partidos comunistas ao apontar a articulação dessas economias feudais com o capital comercial, isto é, a unidade que existe entre o "atraso" feudal com o dinamismo burguês.

${ }^{5}$ A delimitação histórica feita por Ruy Mauro Marini sobre o momento de surgimento da dependência, diverge daquela elaborada por Theotonio dos Santos $(2011$; 1978) e por André Gunder Frank (1970; 1978), que concebem a existência de um período de dependência colonial.

Ao nosso ver, utilizar o conceito de dependência ao lado do conceito de colônia acaba esvaziando o primeiro, já que a situação colonial se impunha através de mecanismos extra-econômicos. Apesar de não haver espaço e nem ser o objetivo deste trabalho, convém qualificar minimamente a diferença do período colonial. Nesse sentido, Florestan Fernandes diz que:

"O sistema básico de colonização e de dominação externas, experimentado por quase todas as nações latino-americanas durante pelo menos três séculos, foi construído de acordo com os requisitos econômicos, culturais e políticos do assim chamado 'antigo sistema colonial'. Em termos jurídicos, a legitimidade de dominação tinha um duplo fundamento, legal e político. Os colonizadores eram submetidos à vontade e ao poder das Coroas de Espanha e Portugal, às quais deviam, como vassalos, obediência e lealdade. Essa identidade de interesses, das Coroas e dos colonizadores, sofreu várias rupturas. Não obstante, permitiu tanto o endosso dos interesses dos colonizadores pelas Coroas como, inversamente, uma orientação de valores pela qual os colonizadores agiam em benefício dos interesses das Coroas. [...]. Sob tais condições societárias, o 
Detectada e explicitada a gênese do capitalismo dependente ${ }^{6}$, convém dar um passo atrás para entender o método que possibilita apreender o movimento do fenômeno da dependência, afim de condensá-lo em períodos históricos. Em outras palavras, devemos entender as leis mais gerais que regem o capitalismo dependente em diferentes etapas históricas do sistema capitalista e das relações imperialistas, o que exige romper com a especialização científica e iniciar, enquanto requisito epistemológico, o caminho de retorno ao pensamento científico que busque a totalidade ${ }^{7}$. Para isso, existe a

tipo legal e político de dominação colonial adquiriu o caráter de exploração ilimitada, em todos os níveis da existência humana e da produção, para o benefício das Coroas e dos colonizadores". Florestan Fernandes. Capitalismo dependente e classes sociais na América Latina. 2009, p. 22-3.

Nessa linha, enfatizando a diferença entre a dependência e a colônia, Marini coloca a questão da seguinte maneira:

"Entretanto, e aí reside a debilidade do trabalho de Frank, a situação colonial não é o mesmo que a situação de dependência. Ainda que se dê uma continuidade entre ambas, não são homogêneas; como bem afirmou Canguilhem, 'o caráter progressivo de um acontecimento não exclui a originalidade do acontecimento'. A dificuldade da análise teórica está precisamente em captar essa originalidade e, sobretudo, em discernir o momento em que a originalidade implica mudança de qualidade. No que se refere às relações internacionais da América Latina, se, como assinalamos, esta desempenha um papel relevante na formação da economia capitalista mundial (principalmente com sua produção de metais preciosos nos séculos 16 e 17, mas sobretudo no 18, graças à coincidência entre o descobrimento de ouro brasileiro e o auge manufatureiro inglês), somente no curso do século 19, e especificamente depois de 1840, sua articulação com essa economia mundial se realiza plenamente. Isto se explica se considerarmos que é com o surgimento da grande indústria que se estabelece com bases sólidas a divisão internacional do trabalho". Ruy Mauro Marini. Dialéctica de la dependencia. 1982, p. 19-20. Tradução nossa, daqui em diante.

${ }^{6}$ É a partir da ótica explicitada que se pode entender o interesse inglês na independência dos países latino-americanos, em especial na América espanhola, expresso na famosa declaração de Lord Canning:

"A América espanhola é livre; e se não administrarmos incorretamente nossos negócios, ela será inglesa". D. A. G. Waddell. A política internacional e a independência da América Latina. In: Leslie Bethell. História da América Latina: Da Independência a 1870, v. III, 2014, p. 253.

7 "As ciências sociais sofrem um infértil processo de fragmentação, endossado pela ideia de especialização. O suposto epistêmico é que na medida em que se alcancem as últimas partes (a parte sem partes), poderemos explicar por agregado a vida social. Dividir e desgarrar, inerentes à fragmentação, levam a perder a atividade unificadora da 
necessidade de esclarecer e determinar o nível de análise adequado para a tarefa proposta neste trabalho ou, em termos marxistas, precisar o grau de abstração da análise ${ }^{8}$, com as categorias próprias de cada nível que, por sua vez, se inter-relacionam e formam um corpo teórico que permitem transitar entre esses distintos níveis: o modo de produção, sistema mundial, padrão de reprodução do capital, formação econômica e social e conjuntura (OSORIO, 2012; 2016).

De acordo com o autor chileno Jaime Osorio, o maior grau de abstração da análise "refere-se à sua capacidade de apreender relações sociais e processos que fundamentam a realidade social, para o que é necessário deixar de lado certos aspectos do movimento histórico a fim de compreender sua essência", de sorte que, "a maior abstração é fortemente histórica, na medida em que aponta a essência daquelas relações e processos". Por outro lado, em níveis menores de abstração, "tais relações e processos vão se tornando mais complexos e passam a apresentar novas características históricas, porque sua essência se expressa sob novas e diversas formas e particularidades" (OSORIO, 2012, p. 38).

A noção mais abstrata, o modo de produção, ilumina o fato de que as relações sociais são estabelecidas pelos seres humanos para dar conta de resolver os problemas da "produção e reprodução econômicopolítica da vida em comum, sob conhecimentos e desenvolvimentos técnicos determinados", sendo estes "os elementos fundamentais a ser desvendados para explicar as características históricas da vida em sociedade"9 (OSORIO, 2012, p. 38-9). Nesse sentido, O Capital se

vida social, aquela que lhe outorga sentido nos múltiplos processos. Hoje, dita atividade é a lógica do capital, que como um tornado prende e joga aos ares todas as relações que encontra no seu caminho. Em meio da dispersão reinante, retornar à totalidade é um requisito epistêmico prioritário". Jaime Osorio. Teoría marxista de la dependendencia: historia, fundamentos, debates y contribuciones. Los Polvorines: Universidad Nacional de General Sarmiento, 2016, p. 190. Tradução nossa, daqui em diante.

8 “Além disso, na análise das formas econômicas não podemos nos servir de microscópio nem de reagentes químicos. A força de abstração [Abstraktionskraft] deve substituir-se a ambos". Karl Marx. O Capital. São Paulo: Boitempo, 2013, Prefácio da primeira edição, p. 78.

9 "Em todas as formas de sociedade, é uma determinada produção e suas correspondentes relações que estabelecem a posição e a influência das demais produções e suas respectivas relações. É uma iluminação universal em que todas as demais cores estão 
252 MALDONADO, F. O. Periodização da dependência e padrão de... dedica em desvendar os elementos centrais que definem o modo de produção na etapa capitalista, constituindo categorias e relações que servem como fundamento e ponto de partida para as análises menos abstratas.

Indo adiante, a noção de sistema mundial capitalista destaca a necessidade de entender "problemas como o mercado mundial, a divisão internacional do trabalho, o imperialismo, a dependência, o intercâmbio desigual"10 (OSORIO, 2012, p. 39), entre outros. Com efeito, de acordo com Osorio:

A noção de capitalismo dependente implica um nível de concreção e historicidade em que o capital se fez capitalismo e este se desdobra como sistema mundial. Neste estágio onde o capitalismo mostra sua heterogeneidade enquanto unidade conformada por diversas modalidades de capitalismo: economias imperiais (ou centrais), com capacidade de apropriar-se do valor produzido em outras regiões e economias, e economias dependentes (ou periféricas) que reproduzem condições para serem expropriadas de valor. É a relação o que permite explicar o desenvolvimento das primeiras e o subdesenvolvimento das segundas. Não é desvinculando-as e analisando-as separadamente que poderemos explicar o avanço de umas e o atraso de outras. (OSORIO, 2016, p. 125).

É nesse grau de abstração que Vânia Bambirra entende o capitalismo latino-americano dentro da expansão do capitalismo mundial:

O capitalismo na América Latina se desenvolveu dentro do contexto da expansão e evolução do capitalismo mundial. Em função disso, assumiu formas específicas que, sem negar as leis gerais do movimento do sistema, configuram no continente tipos específicos de capitalismo dependente,

imersas e que as modifica em sua particularidade. É um éter particular que determina o peso específico de toda existência que nele se manifesta". Karl Marx. Gundrisse. São Paulo: Boitempo, 2011, p. 59.

10 'Noções como imperialismo e dependência (ou 'centros' e 'periferias' na antiga linguagem cepalina), ou intercâmbio desigual, por exemplo, oferecem ferramentas para a análise do sistema mundial capitalista e das diferenças e heterogeneidades em matéria de formações econômico-sociais que o capitalismo gera neste nível de análise". Jaime Osorio. Op. cit., p. 122. 
cujo caráter e modo de funcionamento estão intrinsecamente conectados à dinâmica que assume historicamente $\mathrm{o}$ capitalismo nos países centrais. (BAMBIRRA, 2012, p. 33).

Assim, a análise do fenômeno da dependência se inicia no nível de abstração sistêmico que, por certo, já carrega em si uma abordagem histórica mais concreta na medida em que, o capitalismo dependente, mesmo quando apreendido em um determinado momento, não é estanque, mas ao contrário, é o resultado de um processo histórico e social de expansão do sistema capitalista, que se impõem em uma dada etapa. É nesta direção que se pode compreender a célebre frase de Karl Marx, em $O$ dezoito de Brumário de Luís Bonaparte: "os homens fazem a sua própria história", no entanto, "não a fazem de livre e espontânea vontade, pois não são eles quem escolhem as circunstâncias sob as quais ela é feita, mas estas lhes foram transmitidas assim como se encontram" (2012, p. 25).

Desse modo, se no grau mais abstrato desvenda-se a essência do capital em geral, de qualquer capital, de todo capital, como uma relação de dominação social a partir de uma subordinação real da força de trabalho ao capital, nesse grau menos abstrato o capital se faz capitalismo, desdobrando-se em um sistema mundial heterogêneo primado pela desigualdade entre as modalidades particulares de capitalismo, a saber, capitalismo imperialista e capitalismo dependente, que estão intrinsecamente conectados através de uma relação de apropriação e expropriação do valor produzido nas diversas economias; sistema mundial que configura-se, assim, como um movimento contraditório.

Nos parece ser na beirada desse nível de abstração, transitando para um nível mais concreto, que Theotonio dos Santos sugere uma proposta teórica de periodização do capitalismo dependente:

[...] podemos dizer que as formas históricas da dependência estão condicionadas por:

As formas básicas da economia mundial, que têm suas 

próprias leis de desenvolvimento;

o tipo de relações econômicas dominantes nos centros capitalistas e os modos como se expandem para o exterior;

os tipos de relações econômicas existentes no interior dos países que se articulam na condição dependente, no seio das relações econômicas internacionais geradas pela expansão capitalista. (DOS SANTOS, 1978, p. 310, tradução nossa, daqui em diante).

Essa proposta engloba os elementos indicados no nível de abstração sistêmico, mobilizados para periodizar o capitalismo dependente, reclamando por ferramentas analíticas como a transferência de valor e o intercâmbio desigual ou a superexploração da força de trabalho. Com efeito, os dois primeiros pontos levantados por Theotonio dos Santos condizem com a situação de dependência, nas palavras de Bambirra (2012), ou situação condicionante de acordo com o próprio Dos Santos (1978), isto é, com as dinâmicas externas que se expandem em direção aos países dependentes e condicionam e delimitam o espaço dentro do qual ele se reproduz, enquanto que o terceiro ponto condiz com a estrutura dependente (BAMBIRRA, 2012) ou estrutura interna (DOS SANTOS, 1978), em outras palavras com as dinâmicas internas das economias dependentes. Desse modo, de acordo com essa proposta, um requisito fundamental para que se desvende as regularidades que conformam uma determinada etapa histórica do capitalismo dependente, para que seja possível sua periodização, consiste em apreender os influxos externos articulados com as relações socioeconômicas internas, apontando uma certa regularidade nesse movimento.

Um exemplo de como o descompasso na análise dessa dupla articulação (externo/interno), para utilizar a expressão de Florestan Fernandes, pode recair em uma periodização que não capte a totalidade de cada etapa histórica, pode ser visto em Capitalismo dependente e classes sociais na América Latinall (2009), do próprio Florestan Fernandes. $\mathrm{O}$ autor, faz um determinado tipo de periodização que acaba concedendo demasiado peso ao primeiro ponto, a economia mundial,

${ }^{11}$ Especificamente no capítulo 1: Padrões de Dominação Externa na América Latina. 
e, especialmente, ao segundo ponto, a relação econômica dominante nos países centrais e as formas de expansão para os demais países.

É verdade que abordar as etapas históricas da América Latina através de uma análise que priorize um padrão externo de dominação, acaba facilitando uma certa homogeneização da região, ao enfatizar as transformações e os influxos vindos do exterior. Nesse sentido, diz o autor:

Quando uma determinada forma de organização capitalista da economia e da sociedade era absorvida, isso ocorria em consequência de uma mudança de natureza do capitalismo na Europa e nos Estados Unidos, e novos padrões de dominação externa emergiam inexoravelmente. (FERNANDES, 2009, p. 21).

Como é possível notar, esse tipo de periodização perde de vista e não capta em todo o seu enredo, justamente a dinâmica interna da dependência, isto é, o desenvolvimento mesmo do capitalismo dependente.

Para ilustrar a dificuldade de apreender as diversas fases do capitalismo dependente, quando se utiliza uma abordagem que prioriza um padrão de dominação externa, convém recorrer à própria periodização feita nesse texto pelo autor: 1) antigo sistema colonial, que foi "experimentado por quase todas as nações latinoamericanas durante pelo menos três séculos" (FERNANDES, 2009, p. 22); 2) período neocolonial, surgido a partir da desagregação do sistema colonial, foi vigente por "quase quatro ou cinco décadas - do fim do século XVIII até as primeiras três ou quatro do século XIX" (2009, p. 24); 3) período de dominação externa imperialista, em que "o capitalismo dependente surgiu como uma realidade histórica" (2009, p. 26), de modo que este terceiro tipo de dominação externa surgiu "como consequência da reorganização da economia mundial, provocada pela revolução industrial na Europa", em que os "padrões existentes de dominação externa tornaram-se evidentes após a quarta ou quinta década do século XIX e converteram-se numa realidade inexorável nas últimas quatro décadas daquele século" (2009, p. 256); e 4) período do imperialismo total, padrão de dominação externa então em vigor, que "surgiu recentemente [final da década de 1960 
256 MALDONADO, F. O. Periodização da dependência e padrão de... e começo da década de 1970], em conjunção com a expansão das grandes empresas corporativas nos países latino-americanos" (2009, p. 27, colchetes nosso).

Como se vê, esse modelo de periodização pouco consegue sintetizar e expor as condições do capitalismo dependente, já que entende e apresenta o interno a partir das condições externas ${ }^{12}$. Em outras palavras, apesar de se manter no mesmo nível de abstração discutido até o momento, nesse texto, Florestan Fernandes perde de vista o fato de que o sistema mundial se desdobra em capitalismos imperialistas e dependentes que estão em relações, o que exige abordar e articular categorias como as anteriormente mencionadas: mercado mundial, divisão internacional do trabalho, imperialismo, dependência, o intercâmbio desigual e transferência de valor.

Por outro lado, a insuficiência da proposta de Fernandes indica os limites de uma análise que se mantenha nesse nível de abstração, exigindo mais do que a utilização de categorias como transferência

${ }^{12} \mathrm{O}$ próprio Fernandes, desenvolve melhor a questão da periodização, dando a devida atenção ao fator interno, n'A revolução burguesa no Brasil. Diz o autor:

"Não é intrínseco ao capitalismo um único padrão de desenvolvimento, de caráter universal e invariável. Podem distinguir-se vários padrões de desenvolvimento capitalista, os quais correspondem aos vários tipos de capitalismo que se sucederam ou ocorreram simultaneamente na evolução histórica. Além disso, se se toma um mesmo padrão de desenvolvimento capitalista, pode-se verificar que ele é suscetível de utilizações variáveis, de acordo com os interesses estamentais ou de classes envolvidos pelo desenvolvimento capitalista em diversas situações histórico-sociais e as probabilidades que eles encontram de varar o plano das determinações estruturais e de se converterem em fatores da história".

Nesse sentido:

"[...] dependência e subdesenvolvimento não foram somente 'impostos de fora para dentro'. Ambos fazem parte de uma estratégia, repetida sob várias circunstâncias no decorrer da evolução externa e interna do capitalismo, pela qual os estamentos e as classes dominantes dimensionaram o desenvolvimento capitalista que pretendiam, construindo por suas mãos, por assim dizer, o capitalismo dependente como realidade econômica e humana". Florestan Fernandes. A revolução burguesa no Brasil. São Paulo: Global, 2014, p. 161; 262.

Sendo assim, apesar do autor estar preocupado em fazer uma periodização específica do desenvolvimento capitalista brasileiro, nos parece que essa linha de raciocínio pode ser válida para os demais países dependentes da região. Por outro lado, surgem elementos que indicam a necessidade de um menor nível de abstração do estudo. 
de valor e intercâmbio desigual, que indicam a relação entre países dependentes e países imperialistas no bojo de um sistema mundial heterogêneo. Esse nível de análise se torna insuficiente para dar conta de entender a dinâmica do capitalismo dependente, ou de acordo com o terceiro ponto introduzido por Theotonio dos Santos, as relações econômicas no interior dos países que se articulam na condição dependente. Desse modo, para elaborar uma periodização do capitalismo dependente, nos parece necessário um grau de abstração menor ou um grau mais concreto de análise. Nesse sentido, de acordo com a proposta de Jaime Osorio, um método de análise intermediário entre as noções mais abstratas (modo de produção e sistema mundial) e as mais concretas (formação econômico-social e conjuntura), seria o padrão de reprodução do capital.

A noção de padrão de reprodução do capital surge para dar conta das formas como o capital se reproduz em períodos históricos específicos e em espaços geoterritoriais determinados, tanto no centro como na semiperiferia e na periferia, ou em regiões no interior de cada um deles, considerando as características de sua metamorfose na passagem pelas esferas de produção e da circulação (como dinheiro, meios de produção, força de trabalho, novas mercadorias, dinheiro incrementado), integrando o processo de valorização (incremento do valor e do dinheiro investido) e sua encarnação em valores de uso específicos (calças, rádios, celulares, tanques de guerra), assim como as contradições que esses processos geram. (OSORIO, 2012, p. 40-1).

Se, por um lado, essa noção considera certas características que moldam as formas que o capital assume em determinado espaço, por outro lado, isso está diretamente referenciado aos condicionantes externos:

A reprodução do capital assume formas diversas em diferentes momentos históricos, devendo se readequar às mudanças produzidas no sistema mundial e na divisão internacional do trabalho, reorganizando a produção sobre novos eixos de acumulação e/ou novos valores de uso. Isso permite historicizar a reprodução do capital e diferenciar 
Como é possível observar, na citação anterior estão melhor articulados os três elementos indicados por Theotonio dos Santos como condições necessários para desvendar as formas históricas do capitalismo dependente. Assim, para conhecer as faces que o capitalismo pode assumir em uma determinada sociedade ou região, deve-se observar que, dentro de um determinado período histórico, existem setores e ramos que atraem uma maior quantia de investimento, constituindo-se no núcleo dinâmico da acumulação e reprodução capitalista. Analisando determinado período histórico, pode-se observar que o capital privilegia setores que, naquele momento, serão determinantes no seu processo de valorização. Em outras palavras, para "que a reprodução do capital gere um padrão é necessário que reproduza certas pautas por algum tempo, isto é, que sua passagem pelas esferas da produção e da circulação deixe marcas por meio da repetição" (2012, p. 70). Nessa linha, cada "padrão de reprodução do capital apresenta especificidades quanto ao uso que faz do espaço geográfico. O capital intervém no território de maneiras diversas, segundo as necessidades particulares que sua metamorfose exige" (OSORIO, 2012, p. 73).

Com efeito, a noção do padrão de reprodução do capital consiste na periodização do movimento repetitivo de valorização do capital, levando em conta o eixo dinâmico da acumulação capitalista em uma determinada região, país, etc., explicitando os interesses em disputa: a valorização do valor encarnado em determinado valor de uso. É importante levar em consideração que, não obstante os diversos padrões de reprodução de capital vigentes na América Latina serem diferenciados pelo fato de indicarem os setores do capital que se convertem no dínamo da reprodução capitalista naquele período delimitado, esses setores do capital continuam existindo enquanto frações importantes da burguesia quando já não são mais os polos dinamizadores, isto é, quando passam a estar submetidos aos novos setores que ocupam seu espaço como núcleo de acumulação do novo padrão ${ }^{13}$.

\footnotetext{
13 "Em geral, pode-se observar que traços do padrão primário-exportador atravessam a reprodução do capital na região desde o século XIX até nossos dias, no século XXI. Na primeira etapa, como padrão dominante; posteriormente, com tais traços subordinados
} 
Sendo assim, para a apreensão do movimento da reprodução capitalista, surge a necessidade da incorporação de elementos como a:

[...] procedência do dinheiro investido (estatal, privado nacional ou privado estrangeiro); o tipo de máquinas e ferramentas que se empregam; os mercados em que se adquire; o nível de preparação requerido da força de trabalho; as formas de organização da produção (linhas de montagem, círculos de qualidade, trabalho domiciliar etc.); os valores de uso que se produzem; a quais mercados correspondem (bens-salário, bens suntuários ou bens de capital); as economias a que se dirigem os produtos; a mais-valia, o lucro e sua repartição (quanto regressa às matrizes como lucro, quanto é pago por tecnologias e patentes, quanto fica na economia local etc.); entre outros pontos relevantes. (OSORIO, 2012, p. 46-7).

O padrão de reprodução do capital engloba todos estes aspectos mencionados, mas o faz sempre historizando-os, o que permite esclarecer dois aspectos: a) as razões pelo qual o capital se valoriza assumindo um determinado formato, priorizando a produção de determinados valores de uso, num determinado período, configurando, assim, diferentes formações capitalistas. "Não dá no mesmo valorizar o capital produzindo salsichas e produzindo canhões, assinala Marx, para enfatizar que o valor de uso de valorização define as características do capitalismo que será gerado" (OSORIO, 2012, p. 46). Daí decorre-se que o capital produtivo de um e outro são diversos, como diverso é o mercado de consumo, bem como as políticas econômicas estatais originadas como consequência. Em outras palavras, um país que baseia sua economia na produção bélica, sustentará um mercado de consumo para seus produtos, estimulando conflitos armados, repressão policial interna, etc.; b) os processos de

aos novos padrões existentes, readequando-se às novas condições. Assim como ocorre no México, que segue exportando prata, petróleo e hortaliças, em plena marcha do padrão exportador de especialização produtiva, com automóveis, aparelhos de televisão, motores de combustão interna etc. Ou no Chile, que, junto com polpa de madeira, farinha de peixe, uvas e outras frutas e madeiras, mantém a exportação de cobre (refinado e sem refinar) em um nível significativo e, em um nível muito mais abaixo, também a do ouro". Jaime Osorio. "Padrão de reprodução do capital: uma proposta teórica". In: Carla Ferreira; Jaime Osorio; Mathias Luce (Org.). Padrão de reprodução do capital, 2012, p. 78. 
emergência, auge e declínio de determinado padrão de reprodução. Isto supõe analisar as razões econômicas e políticas, ou seja, analisar projetos "de classe de determinados setores do capital", que "se convertem em eixos de acumulação em cada caso" e "projetos de classe de outros setores do capital" que passam, por sua vez, a ocupar "lugares subordinados" (OSORIO, 2012, p. 45). Tais projetos, por seu turno, influem diretamente na sociabilidade das classes dominadas, de modo que, de acordo com o projeto de reprodução do capital adotado em determinada sociedade, tem-se uma agressividade maior ou menor em relação ao mundo do trabalho.

São, portanto, estes dois aspectos da "historicização da reprodução do capital" que possibilitam "contar com melhores ferramentas para compreender a dinâmica dominante, econômica e política, em tempos específicos, e o terreno em que se desenvolvem os conflitos classistas" (OSORIO, 2012, p. 45). Enfim, se a observação de um determinado ciclo do capital pode ser comparada com a análise de uma foto, de uma imagem, o padrão de reprodução do capital consistiria na análise sequencial de diversas fotos, configurando-se em um filme que permite identificar as regularidades de um determinado bloco histórico, com sua rigidez, fluidez e articulações.

Nesse sentido, essa categoria analítica que é eminentemente econômica, acaba conduzindo a reflexão para os elementos políticos que compõe a explicação da conformação de determinado padrão de reprodução do capital.

A análise dos padrões de reprodução permite romper com a fragmentação tão cara para a concepção imperante na ciência moderna. Integram de maneira necessária perguntas clássicas da análise econômica: quem investe, o que produzem, como produzem e para quem produzem. E a resposta a estas interrogantes nos instala necessariamente no campo da política: as decisões de quem, de que classe, frações ou setores se põem em marcha, e sob quais mecanismos de discussão e consulta, tais decisões se implementam; quais consequências econômicas, políticas e sociais essas decisões têm nas formas em que se desenvolve e organiza a vida em comum. (OSORIO, 2016, p. 205).

Com efeito, não "existe nenhum projeto de reprodução que 
possa beneficiar por igual a toda esta ampla e heterogênea gama de sub-agrupamentos humanos inscritos no seio do capital" (OSORIO, 2016, p. 206). Na mesma linha dessa reflexão, Cardoso e Faletto, sem terem como base de sustentação as categorias marxistas, parecem se aproximar dessa perspectiva quando dizem que:

Para adquirir significação, tal análise requer um duplo esforço de redefinição de perspectiva: por um lado, considerar em sua totalidade as 'condições históricas particulares' - econômicas e sociais - subjacentes aos processos de desenvolvimento, no plano nacional e no plano externo; por outro, compreender, nas situações estruturais dadas, os objetivos e interesses que dão sentido, orientam ou animam o conflito entre os grupos e classes e os movimentos sociais que 'põem em marcha' as sociedades em desenvolvimento". (CARDOSO; FALETTO, 2011, p. $33)$.

Sendo assim, através dos instrumentos analíticos explicitados nesse nível de abstração, se torna possível responder com maior clareza como e por que se forjam as diversas modalidades de conflitos e tensões, ou compromissos, combinações e articulações ou ainda mesmo de acomodações entre os "interesses capitalistas 'nacionais' e 'estrangeiros",' sejam eles "convergentes e divergentes, mais ou menos conservadores e mais ou menos liberais, variavelmente compartilhados pela 'grande', 'média' e 'pequena' burguesias [...]" (FERNANDES, 2014, p. 354-355).

No entanto, se a noção de padrão de reprodução do capital, tal como apresentada por Jaime Osorio, coloca em evidência os problemas políticos e sociais, iluminando inclusive os interesses em conflito, ela não parece ser suficiente para dar conta desses novos elementos, ainda que seja o fio condutor até eles. Nesse sentido, a noção de formação econômica e social é uma categoria analítica mais concreta que pode dar subsídios para iluminar outras questões ${ }^{14}$.

${ }^{14}$ Não faremos referência ao nível mais concreto de análise apontado por Osorio, a saber, a noção de conjuntura, por entendermos que esta se insere nos períodos mais regulares de uma determinada conformação histórica do capitalismo dependente. Cabe rapidamente ressaltar que:

"A noção de conjuntura remete a unidades político-temporais em que se produzem modificações significativas na correlação de forças entre os agrupamentos humanos em 
262 MALDONADO, F. O. Periodização da dependência e padrão de...

A noção de formação econômico-social nos remete à constituição do capitalismo em unidades políticoeconômicas e territoriais limitadas. Essas unidades expressam uma contradição do capitalismo como processo histórico: uma vocação planetária que, no entanto, foi levada a cabo tendo de estabelecer-se em Estados nacionais, o que gera soluções (como taxas de lucro diferenciadas), mas também conflitos diversos (por fronteiras que ainda limitam sua ação).

A formação econômico-social deve considerar as relações econômico-políticas existentes nessas unidades e nos agrupamentos humanos que tais relações constituem, assim como os processos que o capital teve e tem de levar a cabo para estabelecer sua ordem, as soluções alcançadas e os conflitos abertos. Determinar o lugar dessas unidades no sistema mundial (economias imperialistas, periferias imperialistas, países dependentes, periferias etc.) constitui um passo inevitável para compreender as determinações nas quais operam e se desenvolvem. (OSORIO, 2012, p. 40).

Em outras palavras, ao direcionar a análise para as formações econômica e sociais dos Estados nacionais, as dimensões políticas e sociais podem ser abordadas com maior complexidade. Nos parece ser este o nível de análise de Cardoso, em determinada altura de seu artigo Notas sobre o estado atual dos estudos da dependência (1976), quando este se preocupa em teorizar os nexos que esclarecem as estruturas dependentes à luz do processo histórico, a relação entre estrutura e história.

Em primeiro lugar, na referência à análise históricoestrutural háum conjunto complexo de supostos sobre o que

conflito e os projetos que encabeçam, tanto no seio de formações econômico-sociais como no do capitalismo como sistema mundial. Enquanto unidade mais concreta, constitui a síntese de múltiplas determinações de processos variados e alimentados pelas unidades mais abstratas".

Jaime Osorio. Padrão de reprodução do capital: uma proposta teórica. In: Padrão de reprodução do capital. Orgs. Carla Ferreira; Jaime Osorio; Mathias Luce. São Paulo: Boitempo, 2012, p. 40. 
seja estrutura, história e a relação entre ambas. Como em qualquer outra perspectiva que utilize a noção de estrutura, se assume que as relações entre as classes, os grupos e as instituições obedecem a regularidades, possuem uma certa rigidez e são articuladas. Entretanto (e também isto é óbvio), as estruturas são concebidas como produto da luta social e como resultado da imposição social. Por consequência, são vistas, ao mesmo tempo, como processos. Noutras palavras, são historicamente repostas num movimento que altera sua conformação presente. (CARDOSO, 1976, p. 375).

Como é possível notar, Cardoso está em um nível de abstração mais baixo, ou em outras palavras, buscando dar subsídios para uma análise mais concreta das dinâmicas das estruturas econômico-sociais à luz do processo histórico, de modo que poderíamos dizer que o autor está preocupado em delimitar um campo de análise mais concreto, em um nível aproximado ao da formação econômico-social. Nesse sentido, Cardoso sugere que:

A ideia de que existe uma explicação histórica-estrutural tem a ver com o processo de formação das estruturas e, simultaneamente, com a descoberta das leis de transformação dessas estruturas. Trata-se de conceber as estruturas como relações entre os homens que, se bem são determinadas, são também, como se viu acima, passíveis de mudança, à medida em que, na luta social (política, econômica, cultural), alternativas novas vão-se abrindo à prática histórica. Neste sentido, o objeto da análise não se reifica em atores, mas se dinamiza em conjuntos de relações sociais. (CARDOSO, 1976, p. 376).

Para o autor, a estrutura é conformada pela dinâmica das relações sociais e tem sua própria lei de transformação a partir da prática histórica; prática que é política, econômica e cultural. Em feito, para Fernando Henrique Cardoso, a abordagem histórico-estrutural consiste em "um método que requer a reconstituição da 'história das relações estruturais' e que, ao fazê-la, reproduz teoricamente a interação assinalada anteriormente entre o conceito e a prática" (CARDOSO, 1976, p. 376). Como foi dito, o autor está em um nível de abstração que calibra a aproximação da lupa analítica para um determinado espaço 
territorial, com uma determinada estruturação econômica política e social, abarcando inclusive o âmbito da cultura.

A complexidade de apreender esse fenômeno histórico consiste, sobretudo, em que tais determinações (econômicas, políticas, sociais e culturais) são oriundas da dupla articulação (aqui entendida como a interação dinâmica entre a situação de dependência e a estrutura dependente), carregando em si o problema concreto da luta e dos interesses de classes em nível internacional e local, que deságua em uma determinada etapa do capitalismo dependente, com uma determinada dominação burguesa, enquanto síntese dessa interação.

Através da análise dos interesses e valores que orientam ou que podem orientar a ação, o processo de mudança deixa de apresentar-se como resultado de fatores 'naturais' - isto é, independentes das alternativas históricas - e começa a perfilar- se como um processo que nas tensões entre grupos com interesses sociais e políticos e orientações divergentes encontra o filtro pelo qual passarão os influxos meramente econômicos. (CARDOSO, 2011, p. 34).

Fernando Henrique Cardoso, é verdade, aponta o caminho pelo qual o método histórico-estrutural deve apreender a multiplicidade de fatores complexos contidos nas formações econômico-sociais dependentes. Contudo, acompanhamos Cardoso até aqui, enquanto autor imerso no debate da Teoria da Dependência que buscou elementos para historicizar o capitalismo dependente no nível de análise dos Estados nacionais. Passando da questão de método para o estudo da dependência, em seu caráter histórico e geográfico (específico), o autor tem dificuldade em determinar o âmbito econômico de uma maneira mais precisa, não obstante ser a partir deste marco mais geral que se desenvolve sua análise sociológica. Nesse sentido, de acordo com as críticas de Bambirra, em Dependência e desenvolvimento na América Latiana (2011):

[...] o âmbito econômico está presente neste estudo somente como um 'marco' muito geral, a partir do qual se desenvolve uma análise essencialmente sociológica. Isto é: o âmbito econômico importa apenas para definir os parâmetros estruturais, enquanto o estudo se centra na 'ação dos diversos grupos', entendida sob o ponto de vista sociológico. Pois 
bem, o âmbito econômico, ao ser considerado apenas como um marco estrutural em sentido genérico, não permite revelar, em toda sua complexidade, a gama intrincada da ação dos diversos grupos e classes sociais que atuam em função de interesses econômicos objetivos, cuja imposição exige a luta pela hegemonia política. Somente a existência desses interesses pode revelar o sentido da ação política e sociológica dos atores, que se manifesta muitas vezes em movimentos sociais aparentemente difusos e incoerentes. $[\ldots]$

Desta forma, é como se estivéssemos vendo um conjunto de dança e percebendo seus movimentos, mas sem poder escutar o som que dá sentido e nexo a suas evoluções. Não há nesta obra, portanto, uma coerência entre a metodologia proposta e sua utilização ampla e rigorosa na análise realizada. Assim, pelas deficiências no âmbito da análise econômica ${ }^{15}$, a análise política e sociológica acaba sendo muito limitada. (BAMBIRRA, 2012, p. 49-50).

Assim, as inconsistências apontadas no trabalho de Cardoso e Faletto revelam que o nível de análise mais concreto, não pode prescindir das categorias próprias dos níveis mais abstratos ${ }^{16}$, mas ao contrário, deve mobilizá-las e articulá-las com as categorias próprias do grau de abstração da análise. Sob esta ótica, reafirmamos a utilidade da noção de padrão de reprodução do capital e suas categorias para desvendar e compreender os "interesses econômicos objetivos" sejam eles dominantes ou em disputa, explicitando as contradições e conflitos ou lutas de classes inerentes ao processo histórico analisado ou, para seguir a ideia de Vânia Bambirra, aumentando o volume da música que dá sentido à evolução do conjunto da dança. É neste sentido que convém considerar adequadamente os três pontos indicados por Theotonio dos Santos, indicados anteriormente, enquanto aspectos que condicionam "não apenas as relações internacionais desses países, mas também suas estruturas internas", isto é, "a orientação da produção, as formas

\footnotetext{
${ }^{15}$ Essa deficiência irá repercutir, por sua vez, na determinação das particularidades, na classificação tipológica, dos países latino-americanos.

${ }^{16}$ Ao levar o ecletismo ao paroxismo, Fernando Henrique Cardoso e Enzo Faletto desmobilizam as categorias marxistas que possibilitariam desvendar os interesses por detrás dos conflitos classistas.
} 
266 MALDONADO, F. O. Periodização da dependência e padrão de... de acumulação de capital, a reprodução da economia e, ao mesmo tempo, sua estrutura social e política" (1978, p. 311).

Somente assim, a análise pode dar conta do desafio de condensar as múltiplas determinações do capitalismo dependente em um período histórico que se ancora em certa regularidade. É nesse sentido que a reflexão do próprio Cardoso deve ser considerada:

A complexidade da periodização a partir da teoria da dependência deriva da própria caracterização da situação de dependência, a qual supõe a articulação entre a economia mundial e as economias locais, entre a dominação internacional e a dominação de classe em cada país dependente. (CARDOSO, 1976, p. 377).

Pois bem, se é verdade que a noção de formação econômicosocial não se limita apenas em reconstituir, enquanto síntese do pensamento, as relações econômicas, mas engloba as relações sociais e políticas de uma determinada localidade em um determinado período, por outro lado, a questão da economia, muito bem identificadas nos três pontos indicados por Dos Santos, acaba se tornando o fio condutor que possibilita iluminar e tecer, simultaneamente, as demais relações constituídas. Foi com esse espírito que Ruy Mauro Marini indicou, ao final de Dialética da Dependência, a necessidade de "determinar a legalidade específica pela qual se rege a economia dependente", isto é, o movimento do capitalismo dependente, esforço que supunha "definir os graus intermediários mediante os quais essas leis vão se especificando" (1982, p. 99).

Tendo isto em mente, a noção de formação econômico-social consiste em um grau de concretude da análise inadequado para realizar um estudo das etapas do capitalismo dependente. Ela deve considerar, é verdade, não apenas a posição do país analisado na divisão internacional do trabalho e se esta economia é imperialista ou dependente, conforme observou Jaime Osorio, mas obrigatoriamente deve estar articulada com a noção do padrão de reprodução do capital que acaba pavimentando e iluminando o caminho para a análise das demais relações constituídas em um determinado período histórico.

À esta altura, nos parece licito propor que a noção de padrão de reprodução do capital, tal como pensada até então por Osorio, acaba 
enclausurando a periodização da dependência ao âmbito exclusivo da economia - ainda que esclarece e ilumine a trama de interesses específicos que norteiam as relações políticas, sociais em determinado espaço territorial. Se entendemos que o modo de produção capitalista não é somente um modo específico de relações de produção atado nas relações econômicas num dado período histórico da humanidade, mas é também uma forma determinada de reprodução de vida mesma dos seres humanos, então se evidencia uma lacuna nesse nível de análise ${ }^{17}$. Ora, não existiriam traços políticos, sociais e ideológicos mais gerais que seriam regulares em um determinado padrão de reprodução do capital? Respondendo positivamente à esta questão, pensamos que assim como é possível identificar certas regularidades na reprodução do capital em si, também é possível identificar certos padrões das relações políticas e sociais, sempre quando os entendemos como elementos da reprodução do capitalismo em determinado momento.

Em efeito, evidencia-se a necessidade de realizar um esforço teórico e de método ${ }^{18}$ para precisar uma noção que seria mais concreta que o padrão de reprodução do capital e mais abstrata do que a noção de formações econômico-sociais; que pudesse dar conta por um lado, de englobar os traços gerais de regularidade não apenas no âmbito econômico, mas no político, no social e no ideológico em um determinado período histórico, e por outro lado que mobilizasse um conjunto de categorias que possibilitasse abarcar não apenas uma unidade político-econômica e territorial limitada em um Estadonacional, mas que servisse como instrumental comum para um espaço geoterritorial mais amplo, conforme a noção de padrão de reprodução do capital $^{19}$. Com efeito, propomos uma noção de Padrão de

17 Essa lacuna poderia ser preenchida parcialmente com a análise das formações econômico-sociais, na medida em que esta se dedica a tecer as múltiplas determinações da sociabilidade em uma determinada localidade. Contudo, não nos parece que seja nesse grau de abstração que podemos identificar as regularidades das relações políticas, sociais e ideológicas, isto é, definir padrões que condensam um determinado modo de reprodução destas relações.

${ }^{18}$ Evidentemente é um esforço que extrapola os limites desse trabalho e que, ademais, deve ser encarado como uma tarefa coletiva que vá na direção oposta a tendência da especialização epistemológica mencionada anteriormente.

${ }^{19}$ Em realidade o padrão de reprodução do capital mobiliza categorias que também dão 
268 MALDONADO, F. O. Periodização da dependência e padrão de... reprodução do capitalismo, como um nível de abstração que viabilize a periodização do capitalismo dependente.

Um exemplo palpável da possibilidade analítica dessa noção pode ser encontrado no próprio Jaime Osorio, quando ele aponta para um padrão de legitimidade, responsável por mobilizar mecanismos que dão uma base de sustentação para a classe dominante na relação mando-obediência.

Nas últimas três décadas do século XX, a América Latina assiste ao esgotamento de uma relação mando-obediência em torno da proteção que o Estado exercia sobre amplos setores sociais, via políticas de emprego, benefícios sociais em matéria de saúde, educação e moradia, proteção laboral e seguridade social. Este remedo em condições de dependência do Estado benfeitor formado nas economias centrais, permitiu a conformação de amplas alianças sociais que - sob o quadro de uma onda cíclica recessiva a nível do sistema mundial e de recessão na região - se tornaram onerosas para o capital.

Com a marcha de novas formas de reprodução do capital, no contexto de uma reorganização da divisão internacional do trabalho, os setores dominantes na região buscaram restabelecer a relação mando-obediência sobre novas bases, fazendo da cidadania, do voto, das eleições e da transição para a democracia, os eixos de um novo padrão de legitimidade. (OSORIO, 2016, p. 213).

Nesse nível de análise conceitos como Padrão de legitimação, Padrão de dominação, Estado benfeitor, Estado de contrainsurgência, autocracia burguesa, ideologia da dependência ${ }^{20}$ entre outros poderiam demonstrar a regularidade de um determinado período histórico que realmente viabilizasse e/ou enriquecesse a periodização do capitalismo

conta de realizar uma análise focalizada em um determinado país.

20 O conceito de ideologia da dependência foi esboçado por nós no trabalho de dissertação de mestrado, defendido em 2017 no Programa de Pós-Graduação em Integração da América Latina, na Universidade de São Paulo (PROLAM-USP). Ali apenas iniciamos uma reflexão sobre a possibilidade da conformação de uma ideologia dominante das burguesias dependentes que condensa alguns aspectos similares que são mantidos em um determinado período histórico. No entanto, esse é ainda um esforço preliminar. 
dependente.

\section{[anclusãu}

A periodização do capitalismo dependente, que efetivamente apreenda as diversas dimensões da reprodução social condensados em uma determinada etapa histórica, ainda é uma tarefa em aberto. Tendo em vista esse problema, cabe dizer que as "análises" sobre a dependência devem partir de uma "situação concreta" para chegar numa "análise concreta", tal qual demonstrou Marx:

O concreto é concreto porque é a síntese de múltiplas determinações, portanto, unidade da diversidade. Por essa razão, o concreto aparece no pensamento como processo da síntese, como resultado, não como ponto de partida, não obstante seja o ponto de partida efetivo e, em consequência, também o ponto de partida da intuição e da representação. (MARX, 2011, p 54).

Trata-se, então, do exercício de se passar do singular para o geral, a partir das particularidades, isto é, num processo de construção de relações hierarquizadas que se especificam e determinam, de sorte que a síntese resultante (a totalidade) apareça não mais como um agrupamento de eventos difusos, mas como um conjunto de relações que se apresentam organizadas no pensamento. Nesse sentido, o movimento metodológico de elevação do singular ao universal vai especificando, através das condições do particular, as relações presentes num conjunto hierarquizado, em que o universal é informado pelo singular através do particular. Metodologicamente, a apreensão e síntese no pensamento é alcançada mediante a produção de categorias que elucidem essas relações hierárquicas e seu movimento. Em suma, esse movimento descrito significa não apenas a caracterização do singular e do particular, mas também como o universal é informado e se mantém a partir daí.

Entendemos que a categoria de padrão de reprodução do capital, produto do estudo de muitos anos de Jaime Osorio e Ruy Mauro Marini, deu uma contribuição efetiva para a tarefa de apreender historicamente o capitalismo dependente. De fato, se já era um erro atribuir um 
270 MALDONADO, F. O. Periodização da dependência e padrão de...

certo esquematismo e negligência do âmbito histórico ao arcabouço teórico constituído por Ruy Mauro Marini e pela Teoria Marxista da Dependência, com a elaboração da categoria de padrão de reprodução do capital, essa acusação se torna ainda mais descabida. Em realidade, a conformação e adequação dessa categoria dentro do arcabouço teórico da Teoria Marxista da Dependência, acabou não apenas enriquecendo essa corrente teórica como demonstrou que, antes de primar pela teoria em detrimento da história ou ser um autor metafísico, Marini estava preocupado em desenvolver categorias analíticas mais gerais para a compreensão da dependência. Em outras palavras, o autor trabalhava em um nível mais abstrato de estudo, sem negligenciar a necessidade de desenvolver categorias intermediárias, como demonstra a citação anterior retirada do Post scriptum de Dialética da Dependência (Em torno a Dialética da Dependência), quando dialogava diretamente com as críticas realizadas por Fernando Henrique Cardoso no artigo Notas sobre o estado atual dos estudos da dependência.

No entanto, dito isto, como ponderamos anteriormente, nos parece necessário um nível de abstração que dê conta não apenas de identificar a regularidade do percurso de reprodução da valorização do valor e de suas encarnações em determinados valores de uso etc., a partir de categorias econômicas ${ }^{21}$, mas também de iluminar outras determinações incidentes na reprodução do capitalismo dependente.

Portanto, a periodização da dependência deve mobilizar e articular categorias econômicas, políticas e sociais que contribuam para iluminar as múltiplas determinações que configuram cada etapa histórica da dependência, e que, em certo sentido, poderiam qualificar inclusive a análise econômica.

\section{Referência Biblingráfica}

\section{BAMBIRRA, Vânia. O capitalismo dependente latino-americano.}

${ }^{21}$ O que acaba desaguando em periodizações eminentemente econômicas como o Padrão agromineiro exportador; o Padrão industrial (em sua etapa internalizada e com certa autonomia e em sua etapa integrada ao capital internacional); e o padrão exportador de especialização produtiva. 
Florianópolis: Insular, 2012.

BIELSCHOWSKY, Ricardo. Pensamento econômico brasileiro: o ciclo do desenvolvimentismo. Rio de Janeiro: Contraponto, 2000.

CARDOSO, Fernando Henrique. "Notas sobre o estado atual dos estudos sobre dependência". In: SERRA, José (Cood.). América Latina: ensaios de interpretação econômica. Rio de Janeiro: Paz e Terra, 1976, p. 364393.

FALETTO, Enzo. Dependência e desenvolvimento na América Latina. Rio de Janeiro: Civilização Brasileira, 2011.

DOS SANTOS, Theotônio. Imperialismo y Dependencia. México D.F.: Ediciones Era, 1978.

A Teoria da Dependência: Balanço e Perspectivas. Florianópolis: Insular, 2015.

FERNANDES, Florestan. Capitalismo dependente e classes sociais na América Latina. São Paulo: Editora Global, 2009.

A revolução burguesa no Brasil: ensaio de interpretação sociológica. São Paulo: Globo, 2014.

FRANK, André Gunder. Lumpenburguesia: lumpendesarrollo dependencia, clase y política en Latinoamérica. Medelín: La oveja negra, 1970.

. Capitalismo y Subdesarrollo en America Latina. México: Siglo XXI, 1978.

LACLAU, Ernesto. Política e Ideologia na Teoria Marxista: capitalismo, fascismo e populismo. Rio de Janeiro: Paz e Terra, 1978.

LÖWY, Michael. $O$ marxismo na América Latina: uma antologia de 1909 aos dias atuais. São Paulo: Fundação Perseu Abramo, 2012.

MARINI, Ruy Mauro. Dialéctica de la dependencia. México D.F.: Ediciones Era, 1982.

. "O ciclo do capital na economia dependente". In: FERREIRA, Carla; OSORIO, Jaime; LUCE, Mathias (Orgs.). Padrão de reprodução do capita: contribuições da teoria marxista da dependência. São Paulo: Boitempo: 2012.

MARX, Karl. Gundrisse. São Paulo: Boitempo, 2011. 
272 MALDONADO, F. O. Periodização da dependência e padrão de... Boitempo, 2012.

O dezoito de Brumário de Luís Bonaparte. São Paulo: . O Capital. Livro I. São Paulo: Boitempo, 2013.

OSORIO, Jaime. "Padrão de reprodução do capital: uma proposta teórica”. In: FERREIRA, Carla; OSORIO, Jaime; LUCE, Mathias (Orgs.). Padrão de reprodução do capita: contribuições da teoria marxista da dependência. São Paulo: Boitempo: 2012.

. Teoría marxista de la dependencia: historia, fundamentos, debates y contribuciones. Los Polvorines: Universidad Nacional de General Sarmiento, 2016.

WADDEL, D.A.G. "A política internacional e a independência da América Latina. In: BETHELL, Leslie (Org.). História da América Latina: Da Independência a 1870. São Paulo: Editora da Universidade de São Paulo, 2014. 